\title{
Roger H. Unger, 7 March 1924-22 August 2020
}

\author{
Hindrik Mulder ${ }^{1}$
}

Published online: 1 October 2020

(C) Springer-Verlag GmbH Germany, part of Springer Nature 2020

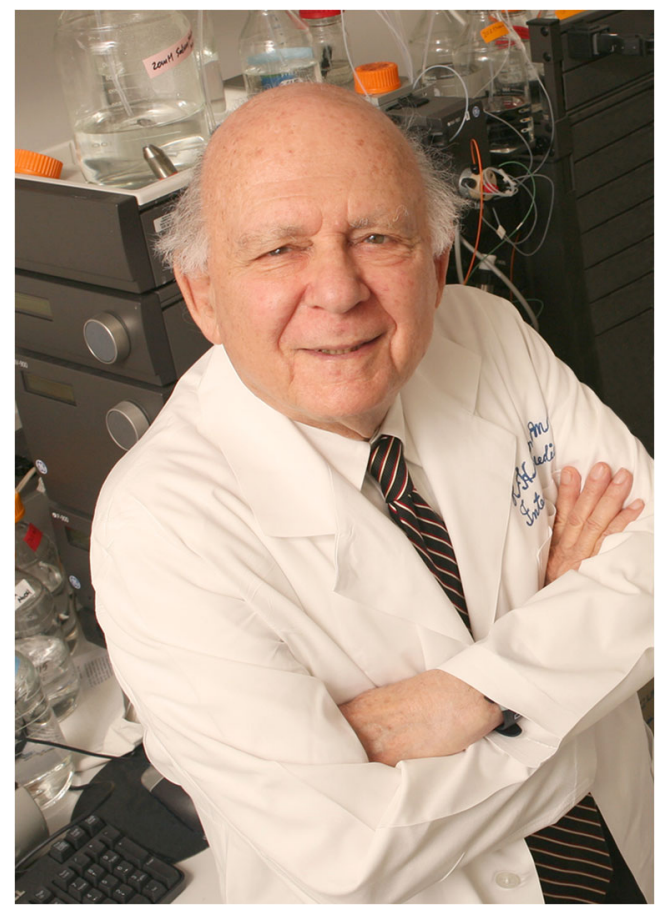

A legend of diabetes research left us on August the 22nd: Roger Unger passed away at the age of 96 . He is survived by his wife, Marlise Unger, four children and his brother, Harlow.

Roger was a medical doctor and began working at the University of Texas Southwestern (Dallas, TX, USA) in 1956. He remained there for his whole career until he retired this summer. In Dallas, he founded the Touchstone Center for

Hindrik Mulder

hindrik.mulder@med.lu.se

1 Unit of Molecular Metabolism, Lund University Diabetes Centre, Malmö, Sweden

Diabetes Research, where he served as director between 1986 and 2007. He held the Touchstone/West Distinguished Chair in Diabetes Research. His clinical practice as an endocrinologist was at Dallas Veterans Affairs Medical Center.

Roger received numerous awards for his groundbreaking research. Among these were the most prestigious prizes given by the ADA and EASD: the Banting Medal and the Claude Bernard Medal. He was elected into the National Academy of Sciences in 1986.

As a scientist, Roger was nonconformist and uncompromising. I believe he felt confined by paradigms and would rather formulate his own, which he did very successfully, with a great and lasting impact on the scientific community. His first groundbreaking finding was that a hormone in addition to insulin is secreted in response to changes in plasma glucose, namely glucagon, which is released in the fasting state to raise plasma glucose. He comprehensively addressed this fundamental mechanism in a series of elegant studies and argued that disruptions in the release of this hormone play an important role in the development of type 2 diabetes. This was controversial at the time but today no one will dispute that type 2 diabetes is a bihormonal disease and that impaired glucagon secretion also plays a crucial role in type 1 diabetes, exacerbating hypoglycaemic events.

The next novel paradigm championed by Roger Unger was that of lipotoxicity (Fig. 1). Until the 1990s, a glucocentric view on the pathogenesis of type 2 diabetes prevailed. Roger and his co-workers published a groundbreaking series of studies on how chronic exposure to lipids interfered with insulin release and functional beta cell mass, thereby paving the way for the development of type 2 diabetes. He also showed that the newly discovered adipocyte-derived hormone leptin could reverse the pathogenic effects of elevated lipids, at least in experimental models. Again, the scientific community needed time to catch up with Roger but, today, the central role of elevated lipids in the disruption of insulin secretion and insulin sensitivity in type 2 diabetes is an integral part of most pathogenetic models of the disease and its complications. 


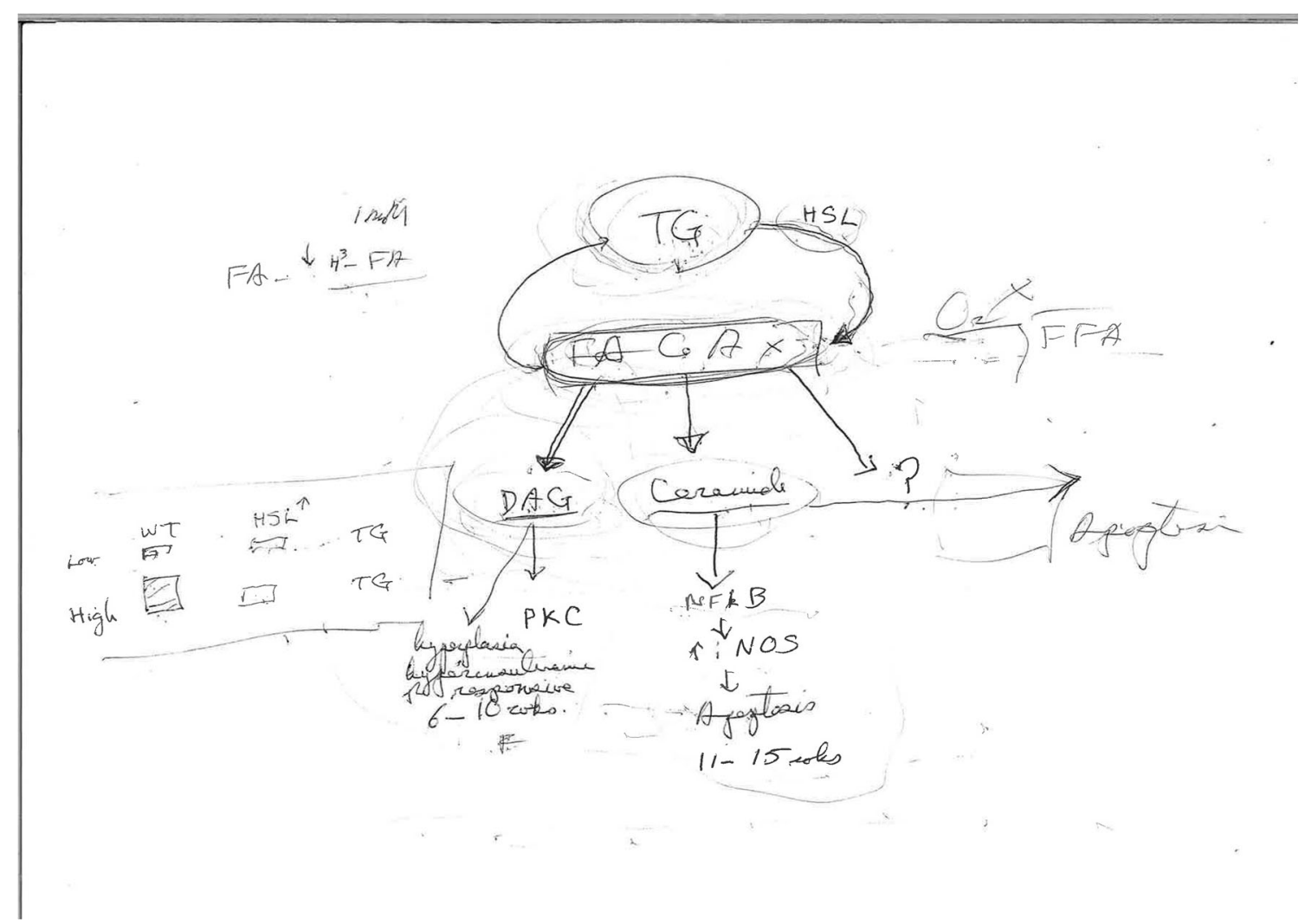

Fig. 1 The lipotoxicity model. Roger Unger and others introduced the lipotoxicity model in the early 1990s. It proposed that prolonged exposure to elevated fatty acids, as in obesity, would lead to harmful deposition of lipids in cells, resulting in dysfunction and death of cells. Unger drew this cartoon for me in 1999 when he outlined the mechanisms of the model for

As a young JDRF postdoctoral fellow at the diabetes research centre in Dallas in the late 1990s I had the great privilege of getting to know Roger and interact with him. He was always immaculately dressed in grey slacks, loafers, a blue club blazer, and shirt and tie; when he came into the office in the afternoon (most mornings were spent at the VA for clinical work), he changed into a white lab coat. The fellows were regularly invited into his office for discussions. Roger was always keen to know what you were doing, providing thoughtful and useful feedback. He had a strange contraption in his office, which would project old-fashioned diapositives on a little screen. He used it to enthusiastically show his work; he always willingly and generously explained his science to us young 'uns. I was a bit starstruck but also profoundly influenced by the passion with which he spoke me. He kindly added hormone-sensitive lipase ('HSL'), which degrades cellular triacylglycerol and which I was working on at the time. DAG, diacylglycerol; FA-CoAx, fatty acyl-coenzyme As; FFA, free fatty acids; iNOS, inducible nitric oxide synthase; PKC, protein kinase C; TG, triacylglycerol; WT, wild type

of his science and ideas, and the beauty and rigour of his theories. The first time I visited the diabetes research centre in Dallas and presented my graduate work, Roger asked me whether I would recommend buying shares in the company that was exploiting the new hormone I was researching. The question caught me completely off guard; my answer to his ingenious question would, I later realised, reveal whether I really believed in my work.

Roger Unger made groundbreaking discoveries in research. He was a warm and generous person. He will be sorely missed.

Publisher's note Springer Nature remains neutral with regard to jurisdictional claims in published maps and institutional affiliations. 